\title{
Thermal Hazard Characteristics of Unsaturated Polyester Resin Mixed with Hardeners
}

\author{
Kewei Ren and Yunting Tsai *(D) \\ School of Chemical Engineering and Technology, Xi'an Jiaotong University, Xi'an 710049, China; \\ renkewei@stu.xjtu.edu.cn \\ * Correspondence: tsaiyt@xjtu.edu.cn; Tel.: +86-1580-292-8628
}

Citation: Ren, K.; Tsai, Y. Thermal Hazard Characteristics of Unsaturated Polyester Resin Mixed with Hardeners. Polymers 2021, 13, 522. https://doi.org/10.3390/ polym 13040522

Academic Editor: Chin-Lung Chiang Received: 26 December 2020

Accepted: 2 February 2021

Published: 10 February 2021

Publisher's Note: MDPI stays neutral with regard to jurisdictional claims in published maps and institutional affiliations.

Copyright: (c) 2021 by the authors. Licensee MDPI, Basel, Switzerland. This article is an open access article distributed under the terms and conditions of the Creative Commons Attribution (CC BY) license (https:// creativecommons.org/licenses/by/ $4.0 /)$.

\begin{abstract}
Unsaturated polyester resin (UP) is a critical polymer material in applications of many fields, such as the chemical industry, military, and architecture. For improving the mechanical properties, some hardeners, such as methyl ethyl ketone peroxide (MEKPO) or tert-butyl peroxy-2ethylhexanoate (TBPO), can trigger the curing reaction in UP polymerization, which causes that UP changes the structure from monomer to polymer. However, polymerization is a strong exothermic reaction, which can increase the risk of thermal runaway reaction in UP. Therefore, the mechanisms and characteristics in the thermal runaway reaction of UP mixed with hardeners should be studied for preventing and controlling UP explosion. The thermal hazards of UP mixed with hardeners were determined by thermogravimetric analyzer (TGA) and differential scanning calorimetry (DSC) analysis. According to the results, UP mixed with MEKPO exhibited a more violent mass loss and exothermic reaction than UP mixed with TBPO. Furthermore, the thermal runaway reactions of UP mixed with MEKPO or TBPO with different mixing proportions of 1:1, 3:1, and 5:1 were determined. Irrespective of MEKPO or TBPO, the mixing proportions of 3:1 exhibited a high onset temperature and low enthalpy of curing reaction $\left(\Delta H_{\text {exo }}\right)$. This demonstrated that this proportion was safer during UP polymerization. The results of this study can provide useful information for preventing UP explosion and developing polymerization technology.
\end{abstract}

Keywords: curing reaction; polymerization; thermal runaway reaction; safer operating condition; explosion

\section{Introduction}

Unsaturated polyester resin (UP), which is a critical polymer, is widely applied in many fields, such as the chemical industry, military, and architecture. Furthermore, China has the largest production of UP in the world. For the applications in many fields and better mechanical properties, hardeners are used to carry out the curing reaction for UP polymerization, thereby changing the properties of UP from liquid to solid. However, polymerization is a strong exothermic reaction. If heat generation is too fast or heat remove rate is slower than heat generation, a considerable heat can accumulate in the reaction system, thereby increasing the risk of the thermal runaway reaction, even fire and explosion [1-6]. Therefore, the thermal hazard of UP mixed with hardeners should be closely studied.

Many studies have investigated the material properties for UP after the curing reaction. Hong et al. explored the effects of the chain length of acid on the curing reaction of UP. The curing rate of UP became slower with the increase in the chain length of saturated aliphatic binary carboxylic acid, which can retard the curing process of UP [7]. Chu et al. investigated the properties of products in vinyl ester-unsaturated polyester resin with adipic acid, $\mathrm{CaCO}_{3}$, and polymer vinyl acetate after the curing reaction. Curing reaction was related to anti-shrinkage, and a decrease in the curing degree can increase the effects of anti-shrinkage [8]. Xu et al. reported that some promoters can shorten the curing time and temperature in the curing reaction [9]. Furthermore, the flame retardancy of UP mixed 
with flame retardants was explored. Bai et al. synthesized a sort of phosphorus-containing star-shaped flame retardant, which can considerably improve the flame retardancy of UP in both gas and condensed phases at the same time [10]. Zhao et al. designed a novel organophosphorus polymeric flame retardant, which was synthesized by hydroxyphenyl imino methyl phenol spirocyclic pentaerythritol diphosphonate, incorporated into the UP monomer [11]. Salasinska et al. developed several kinds of novel flame retardants for UP with high nitrogen content, but some of the retardants may affect the curing process [12]. Boulkadid et al. summarized the various methods for improving and optimizing the curing reaction of high-energy composite materials [13]. Bessa et al. investigated the curing kinetics of bisphenol A-based benzoxazine under non-isothermal and isoconversional kinetic methods by differential scanning calorimetry (DSC) technique [14].

In the past, the curing properties of UP were fully investigated. However, if human error, overfeeding, or equipment failure happen in the cross-linking polymerization of UP, considerable amounts of hardeners may enter into the polymerization system and react with UP, thereby increasing the risk of thermal hazards in UP mixed with hardeners [15]. Furthermore, the thermal hazard characteristics of UP mixed with hardeners were rarely explored, which can cause some faulty experiences in preventing and controlling the thermal runaway of UP, thereby resulting in more serious accidents [16,17]. In this study, critical thermal stability parameters, such as mass loss, mass derivative, onset temperature $\left(T_{0}\right)$, peak temperature $\left(T_{p}\right)$, and enthalpy of curing reaction $\left(\Delta H_{\text {exo }}\right)$, were used to evaluate the thermal hazard of UP mixed with two commercial hardeners, methyl ethyl ketone peroxide (MEKPO) and tert-butyl peroxy-2-ethylhexanoate (TBPO), by thermogravimetric analyzer (TGA) and DSC analysis. This result can provide useful information for inherently safer design of UP during its use, transportation, storage, or deposit and for developments of polymerization technologies.

\section{Materials and Methods}

\subsection{Samples}

UP (6120-TA) with 30\% styrene was provided by En Chuan Chemical Industry, Taichung, Taiwan. Methyl ethyl ketone peroxide (MEKPO) and tert-butyl peroxy-2ethylhexanoate (TBPO), which were purchased from ACE Chemical Corporation, Taoyuan, Taiwan, were stored in sealed containers in a dry and ventilated environment, and the storage temperature should be lower than $4{ }^{\circ} \mathrm{C}$. The mixing proportions of UP mixed with TBPO or MEKPO were 1:1, 3:1, and 5:1. For simplification, UP mixed with TBPO or MEKPO is termed UP-TBPO or UP-MEKPO, respectively.

\subsection{Methods}

TGA (Pyris1, PerkinElmer, Waltham, MA, USA) was used to investigate the mass loss and mass derivative of UP, UP-MEKPO, and UP-TBPO. The mass of pure UP was $3.0-3.5 \mathrm{mg}$. The heating rates were $10,15,20$ and $25^{\circ} \mathrm{C} / \mathrm{min}$, and the temperature range was $30-800^{\circ} \mathrm{C}$ under a nitrogen atmosphere at $20 \mathrm{~mL} / \mathrm{min}$. DSC (DSC 821e, Mettler-Toledo, Greifensee, Switzerland) was used to observe the exothermic reaction of UP, UP-MEKPO, and UP-TBPO, which can obtain critical thermodynamic parameters, such as $T_{0}, T_{\mathrm{p}}$, and $\Delta H_{\text {exo }}$. The masses of UP mixed with hardeners for $1: 1,3: 1$, and 5:1 were 3.5-4.0, 4.0-5.5, and $6.0-6.5 \mathrm{mg}$, respectively. The heating rates were $2,4,8$, and $16{ }^{\circ} \mathrm{C} / \mathrm{min}$, and the temperature range was $30-300{ }^{\circ} \mathrm{C}$ under a nitrogen atmosphere at $20 \mathrm{~mL} / \mathrm{min}$. Moreover, oven heating was used to carry out the curing reaction for UP-TBPO or UP-MEKPO at $150{ }^{\circ} \mathrm{C}$ and $20 \mathrm{~min}$.

\subsection{Kinetic Analysis}

Kinetic studies were conducted by the Kissinger method [18-21], as given in Equation (1):

$$
\frac{\mathrm{d} \alpha}{\mathrm{d} T}=\frac{\mathrm{A}}{\beta} \exp \left(-\frac{E_{\mathrm{a}}}{\mathrm{RT}}\right) f(\alpha)
$$


where $\alpha$ is degree of conversion, $T$ is absolute temperature, $\beta$ is heating rate, $R$ is gas constant $[8.314 \mathrm{~J} /(\mathrm{mol} \cdot \mathrm{K})]$, A is pre-exponential factor, $E_{\mathrm{a}}$ is activation energy, $f(\alpha)$ is mechanism function.

When $T$ is equal to $T_{\mathrm{p}}$, Equation (2) can be obtained by taking natural logarithm of Equation (1).

$$
\ln \left(\frac{\beta}{T_{\mathrm{p}}^{2}}\right)=\ln \left(\frac{\mathrm{AR}}{E_{\mathrm{a}}}\right)+\ln \left[\frac{-\mathrm{d} f(\alpha)}{\mathrm{d} \alpha}\right]_{\alpha_{\mathrm{p}}}-\frac{E_{\mathrm{a}}}{\mathrm{R} T_{\mathrm{p}}} .
$$

Therefore, the slope of plot of $\ln \left(\frac{\beta}{T_{\mathrm{p}}^{2}}\right)$ versus $\left(\frac{1}{T_{\mathrm{p}}}\right)$ can be used to determine the apparent activation energy $\left(E_{\mathrm{a}}\right)$, and the mechanism function does not need to be considered $[20,21]$.

\section{Results and Discussion}

Figure 1 displays the mass and mass derivative curves for pure UP at the heating rates of $10,15,20$, and $25^{\circ} \mathrm{C} / \mathrm{min}$. We conducted three replications for thermogravimetry (TG) experiments. The mass of UP gradually declined with the increase in the temperature. Two obvious mass loss stages were observed in the thermal decomposition of UP at the heating rates of 10,15 , and $25^{\circ} \mathrm{C} / \mathrm{min}$. The first peak occurred in the temperature range of $30-200{ }^{\circ} \mathrm{C}$ and second one occurred in the range of $220-500{ }^{\circ} \mathrm{C}$. Because $30 \%$ styrene existed in UP, the first curve was styrene volatilization and second one was UP decomposition. However, UP exhibited three mass loss stages at the heating rates of $20^{\circ} \mathrm{C} / \mathrm{min}$. The first stage was the volatilization of styrene, the second one was the UP decomposition, and third one was the UP residues decomposition. Because the volatilization of styrene and UP residues decomposition depended on the content levels of styrene and impurity, the thermal curves of the first and third stages may have slight differences in the TG analysis. Furthermore, the second stage of UP decomposition exhibited a great regularity and reproducibility with increasing the heating rates, which corresponded to typical TG results. Therefore, the results are reliable. Table 1 displays the related characteristic parameters for UP tested by TGA.

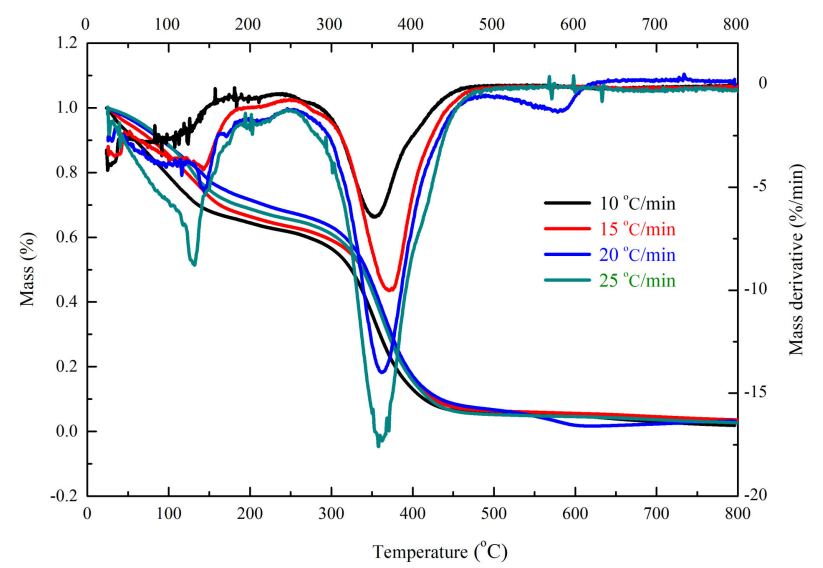

Figure 1. Mass and mass derivative curves of pure unsaturated polyester resin (UP) at heating rates of $10,15,20$, and $25^{\circ} \mathrm{C} / \mathrm{min}$.

Figure 2 displays the mass and mass derivative curves of UP-MEKPO and UP-TBPO after and before oven heating. Three mass loss stages existed in UP-MEKPO before oven heating. The first peak was also styrene volatilization. Because the second and third peaks were close to the decomposition temperature of MEKPO and UP, respectively, these two peaks were individually MEKPO and UP decomposition [22]. However, only one mass loss curve existed in UP-MEKPO after oven heating. Because the decomposition temperature of styrene was lower than $200{ }^{\circ} \mathrm{C}$ and a curing reaction of UP-MEKPO occurred after oven heating, the first and two curves cannot be observed. Moreover, the mass loss of third 
curves after oven heating was higher than before one, which indicated that the UP and the product of UP-MEKPO were simultaneously decomposed in this stage. The mechanisms of curing reaction in UP-MEKPO were determined.

Table 1. Related characteristic parameters for pure unsaturated polyester resin (UP) tested by thermogravimetric analyzer (TGA).

\begin{tabular}{|c|c|c|c|c|c|c|c|c|c|c|}
\hline $\begin{array}{c}\beta \\
\left({ }^{\circ} \mathrm{C} / \mathrm{min}\right)\end{array}$ & $\begin{array}{l}T_{01} \\
\left({ }^{\circ} \mathrm{C}\right)\end{array}$ & $\begin{array}{l}T_{\mathrm{p} 1} \\
\left({ }^{\circ} \mathrm{C}\right)\end{array}$ & $\begin{array}{l}\text { Mass } \\
\text { Loss } \\
(\mathbf{w t} \%)\end{array}$ & $\begin{array}{c}T_{02} \\
\left({ }^{\circ} \mathrm{C}\right)\end{array}$ & $\begin{array}{l}T_{\mathrm{p} 2} \\
\left({ }^{\circ} \mathrm{C}\right)\end{array}$ & $\begin{array}{l}\text { Mass } \\
\text { Loss } \\
(\mathrm{wt} \%)\end{array}$ & $\begin{array}{c}T_{03} \\
\left({ }^{\circ} \mathrm{C}\right)\end{array}$ & $\begin{array}{l}T_{\mathrm{p} 3} \\
\left({ }^{\circ} \mathrm{C}\right)\end{array}$ & $\begin{array}{l}\text { Mass } \\
\text { Loss } \\
(w t \%)\end{array}$ & $\begin{array}{l}\text { Char } \\
\text { Residue } \\
(w t \%)\end{array}$ \\
\hline 10 & 30.1 & 128.2 & 36.3 & 263.3 & 354.5 & 61.8 & - & - & - & 1.9 \\
\hline 15 & 33.4 & 128.5 & 34.3 & 264.2 & 371.1 & 62.2 & - & - & - & 3.5 \\
\hline 20 & 37.2 & 131.7 & 28.9 & 286.2 & 362.2 & 65.8 & 510.6 & 583.8 & 2.1 & 3.2 \\
\hline 25 & 40.6 & 141.3 & 30.1 & 289.6 & 363.9 & 67.3 & - & - & - & 2.6 \\
\hline
\end{tabular}

Abbreviation: $\beta$ is heating rate, $T_{0}$ is onset temperature, $T_{\mathrm{p}}$ is peak temperature, and the numbers (typed in a smaller font) indicate mass loss stages.
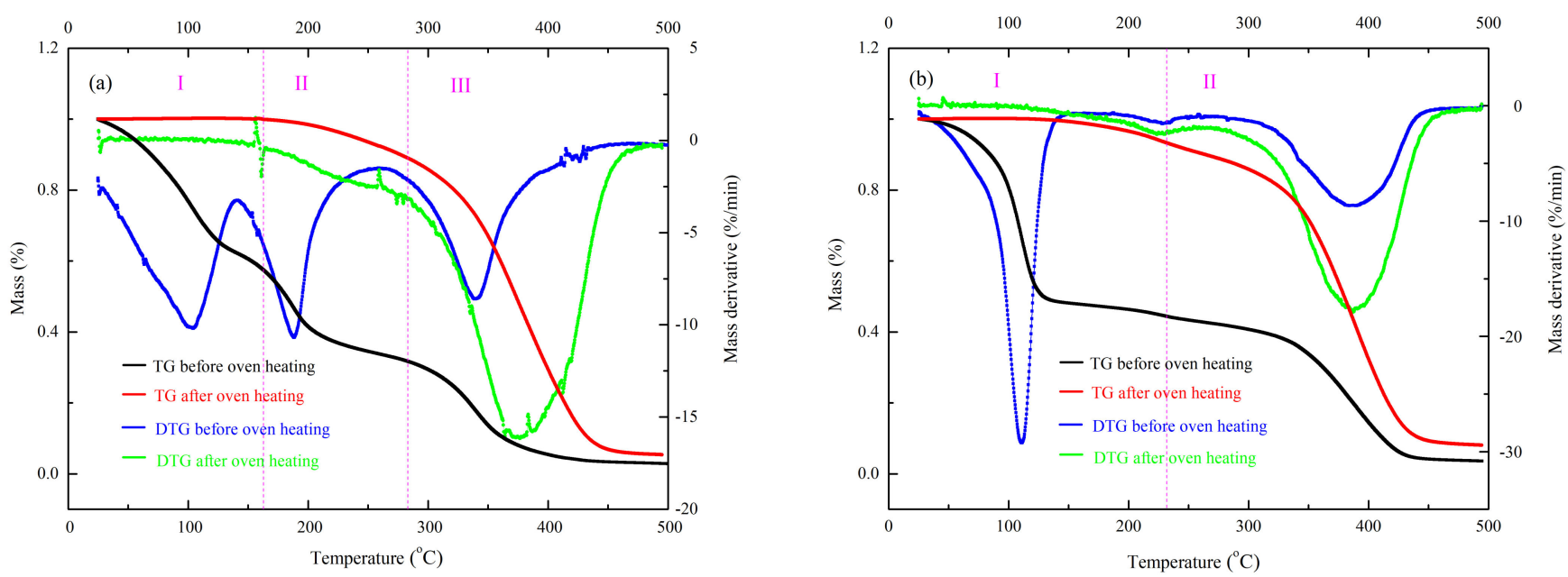

Figure 2. Mass and mass derivative curves of (a) unsaturated polyester resin-methyl ethyl ketone peroxide (UP-MEKPO) and (b) unsaturated polyester resin-tert-butyl peroxy-2-ethylhexanoate (UP-TBPO) after and before oven heating.

Two mass loss stages were observed in UP-TBPO before oven heating and only one existed in after one. Because the decomposition temperatures of styrene and TBPO were close, the combination curves of them occurred in the first stage, and UP decomposition occurred in the second one [23]. Furthermore, because a curing reaction occurred, the curve of UP-TBPO after oven heating was due to the UP decomposition combined with the curing product decomposition. This condition was similar to the results of UP-MEKPO. Table 2 displays the related characteristic parameters for UP-MEKPO and UP-TBPO after and before oven heating tested by TGA.

Figure 3a displays the heat flow versus temperature for UP-MEKPO with different mixing proportions of $1: 1,3: 1$, and $5: 1$ at a heating rate of $4{ }^{\circ} \mathrm{C} / \mathrm{min}$. DSC results were used to observe the exothermic characteristics of the curing reaction of UP mixed with hardeners. Two exothermic curves can be observed in UP-MEKPO. Because the thermal decomposition temperature of the curing products in UP-MEKPO was beyond $200{ }^{\circ} \mathrm{C}$, the product decomposition could be excluded. An increase in the UP levels can increase the strength of the first peak. Therefore, the first stage was the heat release in the curing reaction of UP. As seen in Figure 3a, the temperature of the second curves was close to MEKPO decomposition, and an increase in MEKPO levels can increase the heat release, so this stage was the thermal decomposition of MEKPO. In addition, the study by Chi et al. [24] proposed that MEKPO decomposed at $42{ }^{\circ} \mathrm{C}$, but the trace thermal release existed in this stage. The main thermal release curve of MEKPO initialed at $83^{\circ} \mathrm{C}$ and its peak temperature was 
$130{ }^{\circ} \mathrm{C}$, which corresponded to the second stage of UP-MEKPO decomposition. Therefore, the curing mechanisms of UP-MEKPO were determined. The first and second stages were the curing reaction of UP and MEKPO decomposition, respectively. Moreover, when the mixing proportion of UP-MEKPO was 1:1, a low $T_{0}$ not only existed but also the $\Delta H_{\text {exo }}$ was far stronger than the proportions of 3:1 and 5:1, which indicated that the proportion of 1:1 had a high risk of runaway reaction. Moreover, a similar $\Delta H_{\text {exo }}$ existed in the proportions of 3:1 and 5:1, but a higher $T_{0}$ existed in 3:1. This demonstrated that the mixing proportion of 3:1 exhibited a safer condition for the curing reaction of UP-MEKPO. When the proportion of UP-MEKPO was greater than the safe proportion, the heat release of the curing reaction also greatly increased, which may increase the risk of thermal hazards.

Table 2. Related characteristic parameters for unsaturated polyester resin-methyl ethyl ketone peroxide (UP-MEKPO) and unsaturated polyester resin-tert-butyl peroxy-2-ethylhexanoate (UP-TBPO) after and before oven heating tested by TGA.

\begin{tabular}{|c|c|c|c|c|c|c|c|c|c|c|}
\hline Sample & $\begin{array}{l}T_{01} \\
\left({ }^{\circ} \mathrm{C}\right)\end{array}$ & $\begin{array}{l}T_{\mathrm{p} 1} \\
\left({ }^{\circ} \mathrm{C}\right)\end{array}$ & $\begin{array}{c}\text { Mass Loss } \\
\quad(\mathbf{w t} \%)\end{array}$ & $\begin{array}{l}T_{02} \\
\left({ }^{\circ} \mathrm{C}\right)\end{array}$ & $\begin{array}{l}T_{\mathrm{p} 2} \\
\left({ }^{\circ} \mathrm{C}\right)\end{array}$ & $\begin{array}{c}\text { Mass Loss } \\
\quad(w t \%)\end{array}$ & $\begin{array}{l}T_{03} \\
\left({ }^{\circ} \mathrm{C}\right)\end{array}$ & $\begin{array}{l}T_{\mathrm{p} 3} \\
\left({ }^{\circ} \mathrm{C}\right)\end{array}$ & $\begin{array}{c}\text { Mass Loss } \\
\quad(\mathbf{w t} \%)\end{array}$ & $\begin{array}{c}\text { Char } \\
\text { Residue } \\
\left(w^{\prime} \%\right)\end{array}$ \\
\hline $\begin{array}{l}\text { UP + MEKPO (before } \\
\text { oven heating) }\end{array}$ & 37.2 & 104.1 & 37.8 & 149.1 & 189.6 & 29.2 & 285.6 & 340.3 & 31.6 & 1.4 \\
\hline $\begin{array}{l}\mathrm{UP}+\text { MEKPO (after } \\
\text { oven heating) }\end{array}$ & 235.9 & 376.4 & 94.7 & - & - & - & - & - & - & 5.3 \\
\hline $\begin{array}{c}\text { UP + TBPO (before } \\
\text { oven heating) }\end{array}$ & 56.8 & 111.1 & 53.7 & 235.9 & 383.9 & 42.7 & - & - & - & 3.6 \\
\hline $\begin{array}{c}\mathrm{UP}+\mathrm{TBPO} \text { (after oven } \\
\text { heating) }\end{array}$ & 213.4 & 396.5 & 91.9 & - & - & - & - & - & - & 8.1 \\
\hline
\end{tabular}
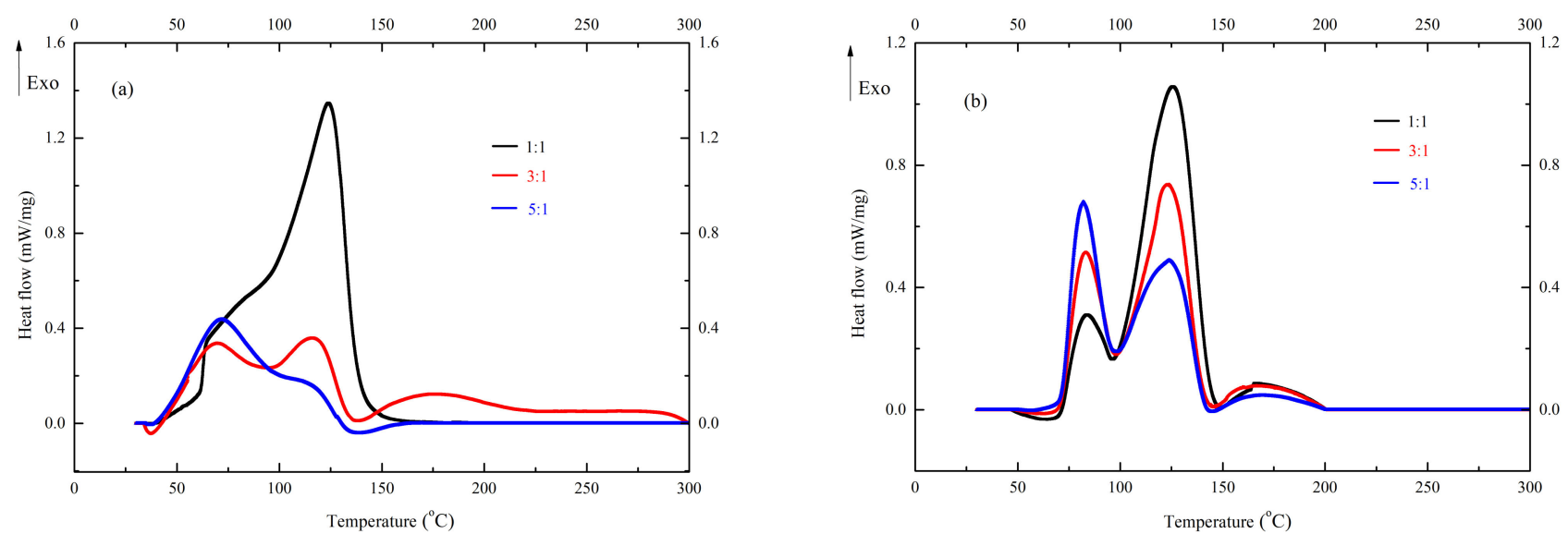

Figure 3. Heat flow versus temperature for (a) UP-MEKPO and (b) UP-TBPO with different mixing proportions of 1:1, 3:1, and $5: 1$ at a heating rate of $4^{\circ} \mathrm{C} / \mathrm{min}$.

In Figure 3b, two exothermic curves also can be observed in UP-TBPO. For a similar condition of UP-MEKPO, an increase in the UP levels can increase the strength of the first peak, and an increase in the TBPO levels can increase the second one. The study by Tsai et al. [25] proposed that TBPO exhibited a single thermal release curve. The onset temperature of TBPO was close to $80^{\circ} \mathrm{C}$ and its peak temperature was $125^{\circ} \mathrm{C}$, which corresponded to the second stage of UP-TBPO decomposition. Therefore, the first and second stages were the curing reaction of UP and TBPO decomposition, respectively. The curing mechanisms of UP-TBPO were determined as well. Moreover, the proportion of 3:1 also exhibited a higher $T_{0}$ and a similar $\Delta H_{\text {exo }}$, compared to 1:1 and 5:1, and the proportion was a dangerous condition. Therefore, the proportion of 3:1 was also a safer condition for the curing reaction of UP-TBPO. Furthermore, the comparisons of exothermic characteristics between UP-MEKPO and UP-TBPO with different mixing proportions were 
determined. According to the results, UP-MEKPO exhibited a similar $\Delta H_{\text {exo }}$, compared to UP-TBPO in different mixing proportions, but a lower $T_{0}$ than UP-TBPO. Therefore, UP-MEKPO had higher risks of a runaway reaction than UP-TBPO. Due to reasons such as human error, overfeeding, or equipment failure, excessive amounts of peroxide added to the system should be avoided.

After confirmations of the safer conditions for UP-TBPO and UP-MEKPO, Figure 4 displays the DSC results of UP-TBPO and UP-MEKPO with different heating rates of 2, 4 , 8 , and $16{ }^{\circ} \mathrm{C} / \mathrm{min}$, which indicated the relationship between exothermic characteristics and heating rates. The $T_{0}$ range of UP-MEKPO with different heating rates was $40.60-67.74{ }^{\circ} \mathrm{C}$, $T_{\mathrm{p} 1}$ was $57.02-103.10^{\circ} \mathrm{C}, T_{\mathrm{p} 2}$ was $103.27-141.39^{\circ} \mathrm{C}$, and $\Delta H_{\text {exo }}$ was $280.34-401.53 \mathrm{~J} / \mathrm{g}$. The $T_{0}$ range of UP-TBPO with different heating rates was $63.94-108.71{ }^{\circ} \mathrm{C}, T_{\mathrm{p} 1}$ was 74.35-106.54 ${ }^{\circ} \mathrm{C}, T_{\mathrm{p} 2}$ was $114.62-140.88^{\circ} \mathrm{C}$, and $\Delta H_{\text {exo }}$ was $355.57-375.79 \mathrm{~J} / \mathrm{g}$. Moreover, an increase in the heating rate can shift the exothermic curve of UP-TBPO and UP-MEKPO to a higher temperature, which exhibited a typical DSC experimental result. Therefore, the data of this study are reliable.
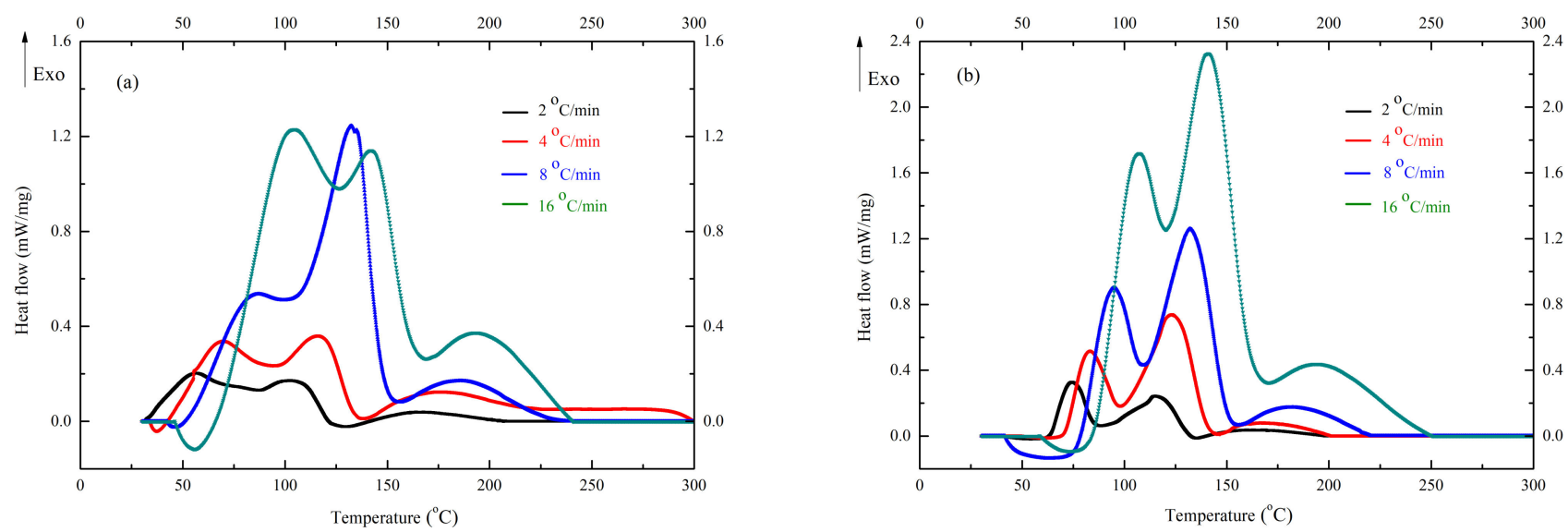

Figure 4. Differential scanning calorimetry (DSC) results of (a) UP-MEKPO and (b) UP-TBPO with different heating rates of $2,4,8$, and $16^{\circ} \mathrm{C} / \mathrm{min}$.

The $E_{\mathrm{a}}$ values of UP-MEKPO and UP-TBPO were calculated by the Kissinger method. Figure 5 displays the linear regression of the plot of $\ln \left(\frac{\beta}{T_{\mathrm{P}}^{2}}\right)$ versus $\left(\frac{1}{T_{\mathrm{P}}}\right)$, which indicated that the slope was $E_{\mathrm{a}}$. The $E_{\mathrm{a}}$ values of UP-MEKPO and UP-TBPO were 39.90 and $65.04 \mathrm{~kJ} / \mathrm{mol}$, respectively. Because $E_{\mathrm{a}}$ means the minimum energy for triggering an initial chemical reaction [26], the risk of thermal runaway reaction was higher in UP-MEKPO, which corresponded to the experimental results.
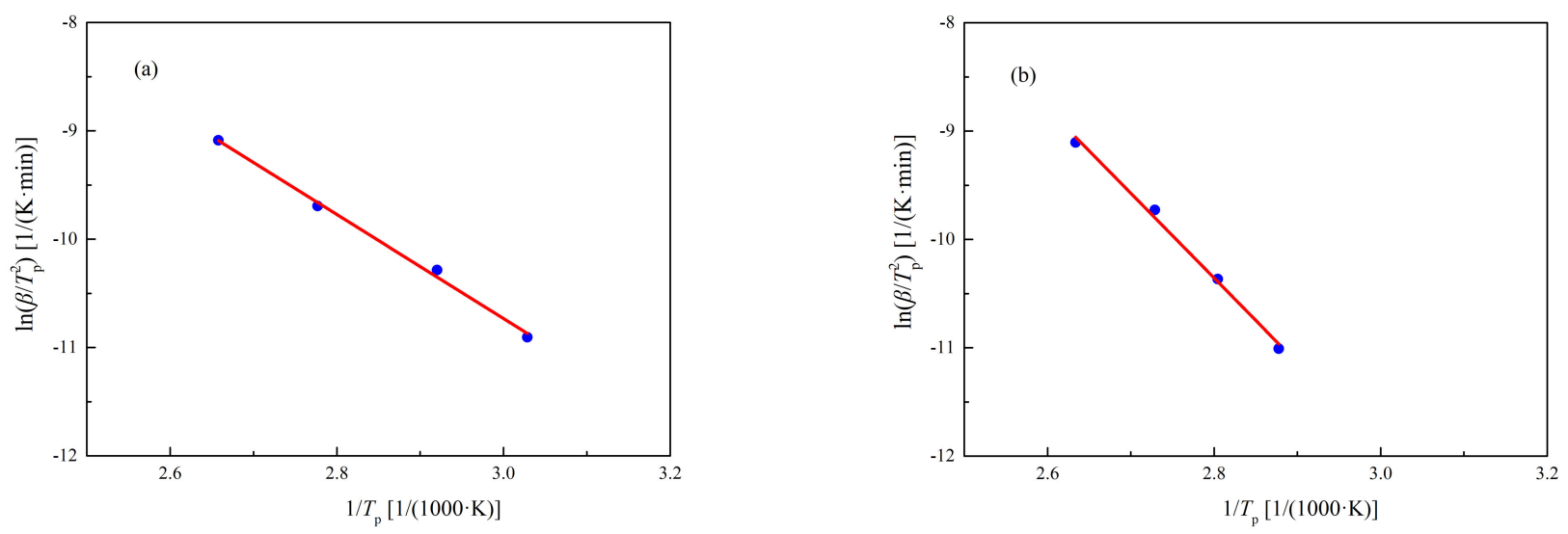

Figure 5. Plot of $\ln \left(\frac{\beta}{T_{\mathrm{P}}^{2}}\right)$ versus $\left(\frac{1}{T_{\mathrm{P}}}\right)$ of (a) UP-MEKPO and (b) UP-TBPO. Here, $\beta$ is heating rate and $T_{\mathrm{P}}$ is peak temperature. 


\section{Conclusions}

This study revealed the mass loss and exothermic characteristics for the curing reactions of UP-TBPO and UP-MEKPO, which can determine the explosion risk of UP during the polymerization. The critical findings are summarized as follows:

The thermal stability of UP and UP mixed with hardeners before or after the curing reaction was confirmed by TGA and DSC results. Because $T_{0}$ can indicate the difficulty degree of the exothermic reaction and $\Delta H_{\text {exo }}$ can indicate the severity of the runaway reaction, the explosion risk can be determined by these two parameters. According to the results, both UP-MEKPO or UP-TBPO had a high $T_{0}$ and low $\Delta H_{\text {exo }}$ at the mixing proportion of 3:1. Therefore, this proportion was a safer condition in the curing reaction of UP-MEKPO or UP-TBPO. At same mixing proportion, UP-TBPO exhibited a higher $T_{0}$ and lower $\Delta H_{\text {exo }}$. Therefore, for considerations of inherently safer design, TBPO was deemed suitable as a hardener for the curing reaction of UP. This study can provide useful information for preventing and controlling the runaway reaction of UP mixed with hardeners and for development of novel hardeners in the future.

Author Contributions: Investigation, K.R.; data curation, Y.T.; writing—original draft preparation, K.R. and Y.T.; supervision, Y.T.; funding acquisition, Y.T. All authors have read and agreed to the published version of the manuscript.

Funding: This research was funded by National Natural Science Foundation of China, grant numbers 2180-8180 and 5190-4229, and Fundamental Research Funds for the Central Universities, grant number xyz012019034.

Institutional Review Board Statement: Not applicable.

Informed Consent Statement: Not applicable.

Data Availability Statement: The data presented in this study are available on request from the corresponding author.

Conflicts of Interest: The authors declare no conflict of interest.

\section{References}

1. Sheng, H.J.; Wang, X.J.; Pan, Z.G.; Chen, X. Thermodynamics and kinetics of one-step curing process for vinyl ester-unsaturated polyester resin in low shrinkage. J. Therm. Anal. Calorim. 2017, 130, 832-833. [CrossRef]

2. Tsai, Y.T.; Yang, Y.; Huang, H.C.; Shu, C.M. Inhibitory effects of three chemical dust suppressants on nitrocellulose dust cloud explosion. AIChE J. 2020, 66, e16888. [CrossRef]

3. Tsai, Y.T.; Ho, S.C.; Huang, A.C.; Shu, C.M. Potential explosion hazard of polyester resin dust formed from a granulation process: Limiting oxygen concentration with different pressures. Appl. Therm. Eng. 2018, 135, 74-82. [CrossRef]

4. Tsai, Y.T.; Liao, J.Y.; Shu, C.M. Explosion characteristics of chlorodifluoromethane and isobutane at high temperature and pressure using a 20-L apparatus. Int. J. Refrig. 2018, 96, 155-160. [CrossRef]

5. Tsai, Y.T.; Yang, Y.; Wang, C.; Shu, C.M.; Deng, J. Comparison of the inhibition mechanisms of five types of inhibitors on spontaneous coal combustion. Int. J. Energ. Res. 2018, 42, 1158-1171. [CrossRef]

6. Yang, Y.; Tsai, Y.T.; Zhang, Y.; Shu, C.M.; Deng, J. Inhibition of spontaneous combustion for different metamorphic degrees of coal by $\mathrm{Zn} / \mathrm{Mg} / \mathrm{Al}-\mathrm{CO}_{3}$-layered double hydroxide. Process Saf. Environ. 2018, 113, 401-412. [CrossRef]

7. Hong, C.M.; Wang, X.J.; Pan, Z.G.; Zhang, Y.F. Curing thermodynamics and kinetics of unsaturated polyester resin with different chain length of saturated aliphatic binary carboxylic acid. J. Therm. Anal. Calorim. 2015, 122, 427-436. [CrossRef]

8. Chu, F.K.; Yu, X.J.; Hou, Y.B.; Mu, X.W.; Song, L.; Hu, W.Z. A facile strategy to simultaneously improve the mechanical and fire safety properties of ramie fabric-reinforced unsaturated polyester resin composites. Compos. Part A-Appl. S. 2018, 115, 264-273. [CrossRef]

9. Xu, X.Q.; Zhou, Q.; Song, N.; Ni, Q.R.; Ni, L.Z. Kinetic analysis of isothermal curing of unsaturated polyester resin catalyzed with tert-butyl peroxybenzoate and cobalt octoate by differential scanning calorimetry. J. Therm. Anal. Calorim. 2017, 129, 843-850. [CrossRef]

10. Bai, Z.M.; Song, L.; Hu, Y.; Gong, X.L.; Yuen, R.K. Investigation on flame retardancy, combustion and pyrolysis behavior of flame retarded unsaturated polyester resin with a star-shaped phosphorus-containing compound. J. Anal. Appl. Pyrolysis 2014, 105, 317-326. [CrossRef]

11. Zhao, D.; Wang, J.; Wang, X.L.; Wang, Y.Z. Highly thermostable and durably flame-retardant unsaturated polyester modified by a novel polymeric flame retardant containing Schiff base and spirocyclic structures. Chem. Eng. J. 2018, 344, 419-430. [CrossRef] 
12. Salasinska, K.; Celiński, M.; Barczewski, M.; Leszczyński, M.K.; Kozikowski, P. Fire behavior of flame retarded unsaturated polyester resin with high nitrogen content additives. Polym. Test. 2020, 84, 106379. [CrossRef]

13. Boulkadid, M.K.; Touidjine, S.; Trache, D.; Belkhiri, S. Analytical methods for the assessment of curing kinetics of polyurethane binders for high-energy composites. Anal. Chem. 2020, 1863768. [CrossRef]

14. Bessa, W.; Trache, D.; Derradji, M.; Ambar, H.; Tarchoun, A.F.; Benziane, M.; Guedouar, B. Characterization of raw and treated Arundo donax L. cellulosic fibers and their effect on the curing kinetics of bisphenol A-based benzoxazine. Int. J. Biol. Macromol. 2020, 164, 2931-2943. [CrossRef]

15. Luo, Q.; Liang, D.; Shen, H. Evaluation of self-heating and spontaneous combustion risk of biomass and fishmeal with thermal analysis (DSC-TG) and self-heating substances test experiments. Thermochim. Acta 2016, 635, 1-7. [CrossRef]

16. Zhang, Y.; Kang, L.; Li, H.; Huang, X.; Huang, L. Characterization of moxa floss combustion by TG/DSC, TG-FTIR and IR. Bioresour. Technol. 2019, 288, 121516. [CrossRef]

17. Meng, F.; Xue, S.; Amyotte, P.; Li, C.; Yuan, C. Characterization of Ti powders mixed with $\mathrm{TiO}_{2}$ powders: Thermal and kinetic studies. J. Loss Prev. Proc. 2020, 66, 104184. [CrossRef]

18. Xu, F.X.; Zhang, X.; Zhang, F.; Jiang, L.Q.; Zhao, Z.L.; Li, H.B. TG-FTIR for kinetic evaluation and evolved gas analysis of cellulose with different structures. Fuel 2020, 268, 117365. [CrossRef]

19. Song, Z.; Li, M.; Pan, Y.; Shu, C.M. A generalized differential method to calculate lumped kinetic triplet of the nth order model for the global one-step heterogeneous reaction using TG data. J. Loss Prev. Proc. 2020, 64, 104094. [CrossRef]

20. Taylor, S.M.; Fryer, P.J. A numerical study of the use of the kissinger analysis of DSC thermograms to obtain reaction kinetic parameters. Thermoch. Acta 1992, 209, 111-125. [CrossRef]

21. Liu, L.; Li, M. Curing mechanisms and kinetic analysis of DGEBA cured with a novel imidazole derivative curing agent using DSC techniques. J. App. Polym. Sci. 2010, 117, 3220-3227. [CrossRef]

22. Yong, H.K.; Mi, J.R.; Han, E.; Kim, K.H.; Yoon, E.S. Hazard prediction of MEKPO decomposition reaction using group contribution method. Theory Appl. Chem. Eng. 2002, 8, 2969-2972.

23. Chang, Y.; Tsai, Y.T.; Pu, Y.; Pan, W.; Shu, C.M. Evaluation of incompatible hazard for TBPO mixed with inorganic acid or base by thermal analysis technology. Disaster Adv. 2014, 7, 35-39.

24. Chi, J.H.; Wu, S.H.; Shu, C.M. Thermal explosion analysis of methyl ethyl ketone peroxide by non-isothermal and isothermal calorimetric applications. J. Hazard. Mater. 2009, 171, 1145-1149. [CrossRef]

25. Tsai, Y.T.; You, M.L.; Qian, X.M.; Shu, C.M. Calorimetric techniques combined with various thermokinetic models to evaluate incompatible hazard of tert-butyl peroxy-2-ethyl hexanoate mixed with metal ions. Ind. Eng. Chem. Res. 2013, 52, 8206-8215. [CrossRef]

26. Yao, F.; Wu, Q.; Yong, L.; Guo, W.; Xu, Y. Thermal decomposition kinetics of natural fibers: Activation energy with dynamic thermogravimetric analysis. Polym. Degrad. Stabil. 2008, 93, 90-98. [CrossRef] 